\title{
Prognostic implications of baseline NT-proBNP before cardiac surgery
}

\author{
Jorge Palazuelos, $\mathrm{MD}, \mathrm{PhD},{ }^{\mathrm{a}}$ Miguel Ángel Rubio Alonso, MD, ${ }^{\mathrm{b}}$ and Patricia Clares Montón, $\mathrm{MD}^{\mathrm{a}}$
}

\footnotetext{
From the ${ }^{\mathrm{a}}$ Interventional Cardiac Unit, Cardiology Department and ${ }^{\mathrm{b}}$ Cardiac Surgery Department, "Gómez Ulla" Central Defense University Hospital, Madrid, Spain.

Disclosures: Authors have nothing to disclose with regard to commercial support.

Received for publication March 2, 2016; accepted for publication March 4, 2016; available ahead of print April 5, 2016.

Address for reprints: Jorge Palazuelos, MD, PhD, Interventional Unit, Cardiology Department, "Gómez Ulla" Central Defense University Hospital, Glorieta del Ejército s/n, 28047 Madrid, Spain (E-mail: jpalaz@gmail. com)

J Thorac Cardiovasc Surg 2016;152:252-3

$0022-5223 / \$ 36.00$

Copyright $(2) 2016$ by The American Association for Thoracic Surgery

http://dx.doi.org/10.1016/j.jtcvs.2016.03.011
}

Acute kidney injury (AKI) is a common but serious complication of coronary artery bypass graft (CABG) surgery, with a reported incidence of $3 \%$ to $30 \%$ depending on the definition used, and is associated with increased short-term morbidity and mortality. ${ }^{1-3}$

In their article in this issue of the Journal, Belley-Cote and colleagues ${ }^{4}$ define postoperative AKI according to Kidney Disease: Improving Global Outcomes Definition and Staging (KDIGO) criteria, ${ }^{5}$ using the maximal change in serum creatinine $(\mathrm{sCr})$ during the first 7 postoperative days compared with the preoperative baseline values. AKI was also defined by either of the following: an increase in $\mathrm{sCr} \geq 0.3 \mathrm{mg} / \mathrm{dL}$ within 48 hours or an increase in $\mathrm{sCr}$ $\geq 1.5$ times baseline known or presumed to have occurred within the previous 7 days. Moreover, AKI was staged for severity according to the following criteria: stage 1, increase in $\mathrm{sCr} \geq 0.3 \mathrm{mg} / \mathrm{dL}$ or to 1.5 to 1.9 times baseline; stage 2, increase in $\mathrm{sCr}$ to 2.0 to 2.9 times baseline; stage 3, increase in $\mathrm{sCr}$ to 3.0 or more times baseline, increase in $\mathrm{sCr}$ to $\geq 4.0 \mathrm{mg} / \mathrm{dL}$, or initiation of renal replacement therapy.

There is no single mechanism that explains cardiac surgery-associated renal injury. It is the result of the interaction of a number of factors, ${ }^{6-8}$ including age, sex, diabetes, poor cardiac function, hypertension, renal dysfunction, use of insulin, preoperative renal dysfunction, contrast agents used for coronary angiography within 7 days of $\mathrm{CABG}$, use of cardiopulmonary bypass, and intraoperative transfusion of packed red blood cells. These factors have been identified as independently associated with an increased risk of postoperative AKI in patients who underwent $\mathrm{CABG}$.

The numerous underlying mechanisms that possibly could induce renal damage include contraction of renal blood vessels, ischemia-mediated oxidative stress, and cytotoxic effects. ${ }^{3,9}$ Most of the known risk factors are unmodifiable. $^{10,11}$ Nonetheless, control of modifiable risk factors can reduce the occurrence of AKI.



Jorge Palazuelos, MD, PhD, Miguel Ángel Rubio Alonso, MD, and Patricia Clares Montón, MD

Central Message

NT-proBNP determination before cardiac surgery provides us a better bedside prognostic information than many other parameters.

See Article page 245 .

Belley-Cote and colleagues ${ }^{4}$ report data from a prospective multicenter observational study of a large cohort of patients at high risk for AKI following cardiac surgery. They used the KDIGO criteria for assessing renal dysfunction. They also described perioperative biomarker changes associated with the development of severe AKI and 1- to 3-year all-cause mortality. Their work in this area represents a very important contribution.

One of the authors' main points regarding the AKI associated with cardiac surgery, that should be worthy of the reader's attention, is that a simple, routine diagnostic test-NT-proBNP_-performed before surgery provides better prognostic information than many other parameters. NT-proBNP is a predictor of complications after cardiac surgery, and the role of preoperative BNP in predicting mortality has been described previously. ${ }^{12}$ However, a strength of the present study is that it provides additional, almost bedside information regarding perioperative events. The authors confirm the results of previous studies, ${ }^{13}$ but also provide direct comparisons of different biomarkers.

Surely, renal function is an important predictor for patients referred for cardiac surgery. Both baseline renal function and the development of renal failure are important predictors of outcome and could modify most of the biomarkers. Various scoring systems, such as EuroSCORE, include renal function to stratify preintervention risk. AKI has been identified as one factor to keep in mind when referring a patient for cardiac surgery, especially if on-pump surgery will be performed. In this context, any useful information, especially if it has bedside usefulness, regarding perioperative risk should be considered relevant. In this analysis, the authors affirm that NT-proBNP provides better prognostic information than 
CK-MB or troponin levels. Changes in this biomarker likely are not as suitable for renal impairment as other biomarkers. The authors have proposed that the higher the preoperative NT-proBNP, the greater the risks of AKI and mortality. Preoperative NT-proBNP was independently associated with the increased incidence of postoperative AKI and 1- to 3-year mortality.

Some questions remain to be answered by the authors, however. First is an explanation of why CK-MB and hsTnT were not associated with renal impairment or 1-year mortality but were associated with 3-year mortality. Second, NT-proBNP and hsTnT are commonly affected by acute coronary syndromes and congestive heart failure, but the number of patients with these disorders was not clear. Also missing is data on the functional class or baseline congestive heart failure symptoms of patients in the preoperative and postoperative periods.

In summary, Belley-Cote and colleagues ${ }^{4}$ have identified the potential usefulness of NT-proBNP in providing prognostic data for patients who have undergone CABG. These preliminary observations should be further assessed in studies exploring the mechanisms and pathophysiology underlying this effect. In addition, future studies should investigate the clinical efficacy of this therapy.

\section{References}

1. Ostermann ME, Taube D, Morgan CJ, Evans TW. Acute renal failure following cardiopulmonary bypass: a changing picture. Intensive Care Med. 2000;26:565-71.

2. Medalion B, Cohen H, Assali A, Vaknin Assa H, Farkash A, Snir E, et al. The effect of cardiac angiography timing, contrast media dose, and preoperative renal function on acute renal failure after coronary artery bypass grafting. $J$ Thorac Cardiovasc Surg. 2010;139:1539-44.

3. Mariscalco G, Lorusso R, Dominici C, Renzulli A, Sala A. Acute kidney injury: a relevant complication after cardiac surgery. Ann Thorac Surg. 2011;92 1539-47.

4. Belley-Cote EP, Parikh CR, Shortt CR, Coca SG, Garg AX, Eikelboom JW, et al; for the TRIBE-AKI Consortium. Association of cardiac biomarkers with acute kidney injury after cardiac surgery: a multicenter cohort study. $J$ Thorac Cardiovasc Surg. 2016;152:245-51.e4.

5. Kellum JA, Lameire N. Diagnosis, evaluation, and management of acute kidney injury: a KDIGO summary (part 1). Crit Care. 2013;17:204.

6. Rosner MH, Portilla D, Okusa MD. Cardiac surgery as a cause of acute kidney injury: pathogenesis and potential therapies. J Intensive Care Med. 2008;23: 3-18.

7. Von Heymann C, Sander M, Foer A, Heinemann A, Spiess B, Braun J, et al. The impact of a hematocrit of $20 \%$ during normothermic cardiopulmonary bypass for elective low-risk coronary artery bypass graft surgery on oxygen delivery and clinical outcome: a randomized controlled study [ISRCTN35655335]. Crit Care. 2006;10:R58.

8. Conlon PJ, Stafford-Smith M, White WD, Newman MF, King S, Winn MP, et al. Acute renal failure following cardiac surgery. Nephrol Dial Transplant. 1999;14: 1158-62.

9. Ranucci M, Ballotta A, Kunkl A, De Benedetti D, Kandil H, Conti D, et al. Influence of the timing of cardiac catheterization and the amount of contras media on acute renal failure after cardiac surgery. Am J Cardiol. 2008;101: $1112-8$.

10. Aronson S, Fontes ML, Miao Y, Mangano DT. Risk index for perioperative renal dysfunction/failure: critical dependence on pulse pressure hypertension. Circulation. 2007;115:733-42.

11. Brown JR, Cochran RP, Leavitt BJ, Dacey LJ, Ross CS, MacKenzie TA, et al Multivariable prediction of renal insufficiency developing after cardiac surgery. Circulation. 2007:116:I139-43.

12. Litton E, Ho KM. The use of preoperative brain natriuretic peptides as a predictor of adverse outcomes after cardiac surgery: a systematic review and meta-analysis. Eur J Cardiothorac Surg. 2012;41:525-34.

13. Holm J, Vidlund M, Vanky F, Friburg O, Hakanson E, Walther S. EuroSCORE I and $\mathrm{N}$-terminal pro-B type natriuretic peptide for risk evaluation: an observational longitudinal study in patients undergoing coronary artery bypass graft surgery. Br J Anaesth. 2014;113:75-82. 